\title{
Idas a campo: relatos das diversidades religiosas de matriz africana no Triângulo Mineiro e Alto Paranaíba
}

Jaqueline Vilas Boas Talga', Solange Inês Engelmann

\section{Resumo}

Neste relato, compartilhamos impressões, sensações, falas dos sujeitos envolvidos e registros fotográficos realizados em dezenove terreiros das religiosidades de matriz africana em cidades do Triângulo Mineiro e Alto Paranaíba, entre eles casas de Candomblés e Umbandas. Todos participaram do projeto de extensão "Por que tanto preconceito: o cotidiano das religiosidades de matriz africana", que procura contribuir para a valorização, a divulgação e a compreensão dessas formas de adorar o sagrado. Nessas trajetórias de idas a campo, encontramos uma considerável quantidade de terreiros existentes na região e uma rica diversidade entre eles, tanto na estrutura do espaço religioso, da organização do culto quanto das práticas religiosas.

\section{Palavras-chave}

Religiosidades de Matriz Africana. Diversidade Religiosa. Candomblés. Umbandas. Registros Fotográficos.

1. Mestrandas em Ciências Sociais pela Universidade Federal de Uberlândia. E-mail: jtalga@yahoo.com.br, solengel03@gmail.com. 


\title{
Field research: stories of african religious diversities in Triângulo Mineiro and Alto Paranaíba
}

\author{
Jaqueline Vilas Boas Talga*, Solange Inês Engelmann*
}

\begin{abstract}
In this report we share the impressions, feelings, statements of the subjects involved and photographic records made in the nineteen places of African religiosity in the cities of Triângulo Mineiro and Alto Paranaiba, including houses of Candomble and Umbandas. All participated in the extension project "Why so much prejudice: the everyday religiosity of African origin", which seeks to contribute to the development, dissemination and understanding of these forms of worship sacred. In these trajectories of field trips we found a considerable amount of local temples in the region and a rich diversity among them, both in the structure of religious space and in the organization of the cult as religious practices.
\end{abstract}

\section{Keywords}

Religiosity of African Origin. Religious Diversity. Candomblés. Umbandas. Photographic Records.

\footnotetext{
* Candidates for a master's degree in Social Sciences at the Federal University of Uberlândia. E-mail: jtalga@
} yahoo.com.br, solenge103@gmail.com 


\section{Introdução}

[...] nunca se deve generalizar, pois não há uma única África, não há um homem africano, não há uma tradição africana válida para todas as religiões e todas as etnias. Existindo grandes constantes (a presença do sagrado em todas as coisas, a relação entre os vivos e os mortos, o sentido comunitário, o respeito religioso pela mãe etc.), mas também há numerosas diferenças: deuses, símbolos sagrados, proibições religiosas e costumes sociais delas resultantes variam de uma religião a outra; de uma etnia a outra; às vezes, de aldeia para aldeia.

Amadou Hampâté Bâ

As religiosidades de matriz africana, como os Candomblés ${ }^{2}$ e Umbandas, encontramse presentes em todo o território brasileiro. Seu modo de "adorar" o sagrado extrapola o espaço físico dos terreiros, e pode ser observado em receitas culinárias, como a utilização do óleo de dendê em muitos pratos; no vestuário; nas músicas; e, principalmente, em letras de compositores e cantores, além de expressar línguas africanas, entre outros. Nesse sentido, seus adeptos podem se orgulhar de seguirem uma religião que possui vários de seus elementos presentes na cultura brasileira.

Porém, mesmo existindo, na atualidade, uma considerável gama de estudos acadêmicos voltados para essa temática, de maneira geral, esse diversificado e rico universo é pouco conhecido, ou melhor, conhecido, porém de forma amplamente distorcida, demonizada e, para o horror dos antropólogos, classificada como uma religião única, esvaziada da diversidade que as constituem.

As distorções e o ódio alimentado por outros seguimentos religiosos têm resultado em vários casos de perseguição aos adeptos das religiosidades de matriz africana - verificados nas ruas e em ambientes de trabalho - e casos de destruição de terreiros ${ }^{3}$ em algumas cidades do Brasil, conforme reportagem intitulada "Ameaça à liberdade de culto", publicada em setembro de 2012 no jornal Brasil de Fato:

Religiosos afrobrasileiros têm sido alvo de perseguição. Motivados por preconceito contra as religiões de matriz africana, fiéis de igrejas evangélicas neopentencostais invadiram e destruíram sete terreiros em Pernambuco desde julho. Para especialista, a intolerância é fruto de desconhecimento e é incentivada por líderes religiosos em rádios e TVs (NAVARRO, 2012, p. 4-5).

Diante dessas e outras constatações, e também de nossas inquietações, procuramos contribuir, mesmo que pontualmente, para a mudança deste cenário estereotipado e ausente de legitimidade nos quais se encontram as religiosidades afro-brasileiras.

Seguindo as contribuições de Paulo Freire (1983), que, na década de 1960, já alertava quanto aos conceitos antagônicos de extensão e comunicação, a ação do educador/pesquisador não deve admitir somente uma voz, mas estimular a transmissão e a distribuição de conhecimento que possibilite múltiplas vozes entre os sujeitos, que lhes gere a independência e a autonomia; sendo algo concreto e abstrato, inserido na realidade histórica das sociedades. Nesse sentido, entendemos a extensão de tal maneira que a comunicação engloba uma troca de saberes, na qual não se levam, mas compartilham-se saberes, conhecimentos, e os sujeitos são compreendidos como

2. Optamos por usar letra maiúscula ao fazermos referência ao Candomblé enquanto religiosidade de matriz africana de modo amplo, de acordo com a metodologia adotada por Silva (1995), em "Orixás na metrópole".

3. Terreiros, casas, centros, barracões, ilês, designam os nomes dos espaços físicos das religiosidades de matriz africana, no Brasil. 
portadores de saberes capazes de transformar a realidade em que vivem e não como "coisas", vazios de qualquer conhecimento.

Nesta perspectiva, elaboramos o projeto de extensão" "Por que tanto preconceito: o cotidiano da religiosidade de matriz africana", vinculado a Pró-reitora de Extensão, Cultura e Assuntos Estudantis e ao Instituto de Ciências Sociais da Universidade Federal de Uberlândia. Como atividade final, foram realizadas exposições fotográficas, no formato de banners, nos quais apresentamos parte dos registros fotográficos realizados nas visitas aos dezenove terreiros das três cidades contempladas pelo projeto (Uberlândia, Ituiutaba e Monte Carmelo, no estado de Minas Gerais). Após a aprovação do projeto na Universidade, como atividade de capacitação da equipe de pesquisa, realizamos um minicurso aberto às comunidades interna e externa intitulado: "Um dialogo com a religiosidade de matriz africana". Além de promover a formação continuada da equipe executora do projeto, esse espaço possibilitou a troca de informações e, para muitos, um primeiro contato com a diversidade religiosa afro-brasileira.

Em seguida, passamos a realização do mapeamento dos terreiros e, principalmente, de pessoas que poderiam nos auxiliar na busca desses espaços, pois, além de encontrar os terreiros, procuramos estabelecer a escolha das casas que seriam visitadas e retratadas, a partir de uma maior diversidade de cultos.

Sendo assim, no decorrer do texto, compartilhamos as principais diferenciações teóricas e práticas encontradas nos terreiros contemplados pelo projeto, juntamente com parte dos registros fotográficos realizados durante as idas a campo. É importante ressaltar que todos os registros fotográficos compartilhados neste trabalho possuem autorização prévia dos sujeitos envolvidos, no caso: os pais e mães de santo, para sua utilização e divulgação pelas pesquisadoras.

\section{As diversidades presentes nas religiosidades de matriz africana pesquisadas}

Os primeiros entraves para a realização do projeto não foram somente descobrir, entrar em contato e mapear os terreiros, mas também encontrar quem financiaria e acreditaria no projeto. Logo, a primeira barreira esteve no nível burocrático institucional e financeiro.

A ideia do que fazer e o projeto já existia, mas necessitávamos do aporte econômico e institucional legitimado. Conquistado este patamar, comoapoio imprescindível da Dra Marili Peres Junqueira, professora do curso de Ciências Sociais da Universidade Federal de Uberlândia, demos início aos contatos iniciais a partir dos laços já estabelecidos em outros momentos de estudo, de manifestações políticas e culturais.

$\mathrm{Na}$ cidade de Monte Carmelo- $\mathrm{MG}^{5}$, tivemos o auxilio fundamental dos familiares da estagiária integrante de projeto de extensão, desde hospedagem, refeições na casa de sua tia, até o auxílio de sua prima, estudante do curso de direito, e sua amiga, trabalhadora doméstica, que nos acompanharam nas duas idas a campo realizadas naquela cidade. Percebemos que essas mulheres conheciam praticamente todos os zeladores(as) e terreiros da cidade.

Algo que chamou nossa atenção foi o alto número de terreiros de Umbanda existentes

4. Participam do projeto Jaqueline Vilas Boas Talga e Marili Peres Junqueira (coordenadoras); Vanesca Tomé Paulino (estagiária) e Solange Inês Engelmann (preparação de imagens e arte final).

5. Monte Carmelo possui 45.799 mil habitantes, de acordo com o Instituto Brasileiro de Geografia e Estatística - IBGE (2010). 
no município, em relação a apenas um de Candomblé e alguns de Quimbanda ${ }^{6}$ (nenhum deles retornou aos nossos contatos). No início do mapeamento, a princípio, alguns moradores e ex-moradores disseram que na cidade não existia esse tipo de religiosidade e que ali encontraríamos apenas alguns benzedores e centros espíritas de linha kardecista.

Ao chegarmos à cidade de Ituiutaba$\mathrm{MG}^{7}$, primeiramente estabelecemos contato com um religioso, que, naquele momento, tentava articular a criação de uma organização em defesa dos religiosos de matriz afro no município, devido às discriminações constantes que quase haviam provocado o fechamento do terreiro de Umbanda de sua esposa por parte do poder público local. O terreiro ao qual o religioso pertence, a princípio participaria de nosso projeto, porém, em um segundo momento, devido à mensagem do mentor espiritual da casa, nos foi negada a intervenção nesse espaço. Entretanto o religioso nos auxiliou plenamente, indicando outros terreiros, nos quais efetivamos o trabalho na cidade.

A partir do primeiro contato, percebemos a existência de um grande número de terreiros de Umbanda e alguns de Candomblé em Ituiutaba-MG. Nas visitas, pudemos observar que nas casas de Candomblé, mesmo nos casos em que a casa "toca", realiza "trabalhos" e cerimônias prioritariamente relacionados à Umbanda, o zelador posiciona-se exclusivamente como do Candomblé. O fato de existirem, no mesmo espaço, momentos e elementos de cultos classificados por muitos como distintos ${ }^{8}$, verificamos, principalmente pela trajetória de vida dos religiosos na nossa região, que a grande maioria deles conheceu as religiosidades de matriz africana, a princípio, por meio da Umbanda e, posteriormente, por intermédio do Candomblé, que chegou à região sudestes mais recentemente. Já na cidade de Uberlândia- $\mathrm{MG}^{9}$, segundo informações da Aliança das Religiões de Matriz Afro-Ameríndia (ARMAFRA), são cerca de 400 terreiros de religiosidade de matriz afro. Desse montante, também percebemos a prevalência das casas de Umbanda, ao mesmo tempo em que constatamos um relativo aumento, principalmente nos últimos quinze anos, dos terreiros de Candomblé. Via de regra, verificamos no município o mesmo movimento identificado por Reginaldo (1991) em São Paulo, no qual muitos dos umbandistas passaram para o Candomblé, onde estabelecem outras modalidades de culto sem abandonar totalmente elementos anteriores. Assim verificamos a manutenção, geralmente (re)elaborada das sessões próprias da Umbanda dentro de um terreiro de Candomblé como,

6. Luiz Mott, em palestra proferida em agosto de 2011, durante o IX Congresso Luso-Afro-Brasileiro de Ciências Sociais, na Universidade Federal da Bahia, em Salvador, apresenta duas versões opostas de concepção da Quimbanda: em uma, é vista enquanto "viado", em Angola, e, na outra, enquanto "diabo" no Brasil. Isso porque foram encontrados, no continente africano, mulheres e homens usando trajes que, culturalmente, são vistos como femininos. Esses homens e mulheres, além de outras atividades, eram sacerdotes e, como tal, dominavam as práticas da adivinhação e de cura. Devido ao tráfego de pessoas para fins escravistas, vieram para o Brasil e aqui continuaram com parte de suas atividades mágico-religiosas, concebidas como feitiçaria aos olhos dos europeus. Sua transfiguração para "diabo", no Brasil, deve-se, a princípio, a uma denominação externa promovida pela visão eurocêntrica de mundo da época; em um segundo momento, parte foi apropriada pelos próprios seguidores, o classificando como a linha de esquerda em contraposição a entidades cultuadas na linha da direita, a Umbanda e a Quimbanda, o bem e o mal, dentro de uma classificação dualista.

7. O município conta com uma população de 97.159 mil habitantes, segundo estimativa do IBGE (2010).

8. Segundo Prandi (1991), dependo da forma como os primeiros cientistas tivessem classificado a Umbanda, ela poderia ser percebida como um tipo de Candomblé.

9. O maior município do Triângulo Mineiro, conta com uma população de 600.285 mil habitantes, segundo estimativa do IBGE (2010). 
por exemplo, antes de iniciar os "trabalhos" da Umbanda, alguns zeladores fazem o xirê, ritual com cantigas e danças próprias do Candomblé.

A partir dos contatos estabelecidos anteriormente, ora por pertencer a esse campo religioso, participar de manifestações e articulações educacionais e políticas (Caminhada Pela Liberdade Religiosa, que, desde 2008, ocorre no Rio de Janeiro; Conferências Municipais Pela Promoção Da Igualdade Racial, entre outros), mapeamos e selecionamos os terreiros, procurando contemplar a diversidade religiosa existente no município. Identificamos, assim, casas de Umbandas, de Candomblés Jeje, Ketu, Angola e Omolokô. Do mesmo modo como nas outras cidades, em Uberlândia também identificamos a existência de casas de Quimbanda, cujo aceite para participar do projeto não se efetivou. Antes de apresentarmos o mapeamento realizado, cabe aqui diferenciar, sucintamente, o Candomblé da Umbanda. Assim, faremos o esforço de explicar de modo simples e didático as distinções entre essas duas religiosidades; distinções estas que perpassam não só o campo do ritual, mas também o campo da fé e da subjetividade. O Candomblé cultua os ancestrais (e/ou as energias, no caso do Omoloko) enquanto elementos da natureza, e também a personificação terrena deste, a saber, na manifestação dos Orixás (Nação Ketu), Inquinces (Nação Angola) e Voduns (Nação Jeje). Por vezes, os ancestrais também se manifestam por intermédio dos erês e caboclos, sendo que seus rituais envolvem o sacrifício de animais, existindo ainda o jogo de búzios, ebós, com cantigas nas línguas africanas correspondentes as nações. Já na Umbanda, detentora de um maior sincretismo com os elementos típicos das religiões europeias e ameríndias, o culto aos Orixás faz-se de modo distinto do Candomblé, além do culto a caboclos, pretos velhos, erês, exus, marinheiros, ciganos, entre outrasentidades que fazem referência a ancestrais característicos do território brasileiro. Outra distinção é que pais/mães de santo, bem como os adeptos que recebem as entidades, ou seja, manifestam em seus corpos as energias dessas entidades, dão consultas (denominadas passes), receitam chás e banhos de ervas, entre outras atividades.

Temos nos Candomblés a diferenciação dos cultos, dos rituais, das cantigas, da língua e de outros elementos, a partir dos grupos africanos provenientes de cada uma das denominadas nações que, no Brasil, irão ser (re)elaboradas mediante as situações econômicas, culturais, históricas, do tráfico negreiro e do sistema escravista, inclusive na sua forma de adorar o sagrado (PARÉS, 2006).

Encontramos em todas as nações uma lógica referente à existência dos ancestrais (que podem ou não ter existido, relacionados a elementos da natureza, como: rochas, rios, plantas, árvores) que irão intermediar a ligação com o que podemos denominar como o "Deus Maior". Segue a exemplificação na tabela abaixo:

Tabela 1 - Relação de cada nação dos Candomblés com o ancestral e o "Deus Maior".

\begin{tabular}{ccc}
\hline Nação & $\begin{array}{c}\text { Nome do } \\
\text { Ancestral }\end{array}$ & $\begin{array}{c}\text { Nome do } \\
\text { "Deus Maior" }\end{array}$ \\
\hline Jeje & Vodum & Mawu \\
Ketu & Orixá & Olorun \\
Bantu (Angola) & Nkisi & Zambi \\
\hline
\end{tabular}

Fonte: Relatos obtidos a partir de religiosos durante as idas a campo do projeto de extensão.

\section{Panorama dos Candomblés e Umbandas no Triângulo Mineiro e Alto Paranaíba}

Procuramos aqui compartilhar alguns elementos que demonstram as diversas formas de cultuar o "sagrado" em cinco dos dezenove terreiros de Candomblé e de Umbanda que participaram do projeto. 
Para tanto, primeiramente, consideramos de fundamental importância informar que todos os registros fotográficos aqui compartilhados receberam autorização, por escrito, das mães e pais de santo das casas envolvidas no projeto de extensão para sua divulgação. Todos os registros foram verificados e liberados por eles: desde os locais permitidos para a realização até as imagens a serem utilizadas para a exposição e demais trabalhos que as pesquisadoras envolvidas viessem a realizar.

Figura 1 - Foto de membros em casa de Candomblé Nação Ketu.

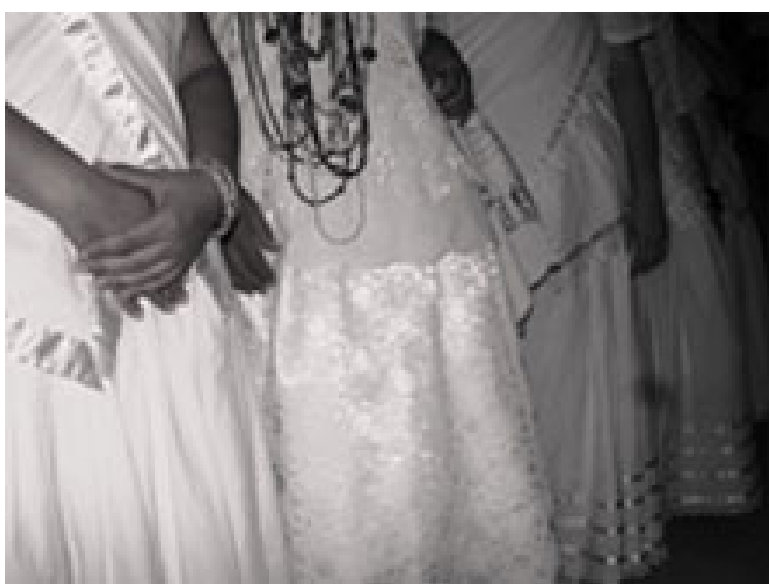

Fonte: Acervo do projeto. Dados: Ilê Alaketu Axê lji Aye (Casa de Alaketu e do Rei do Mundo). Fundação: 14/01/2012. Local: Monte Carmelo-MG. Zeladora: Yalorixá Eleida D'Obaluaê.

Durante a pesquisa, essa foi a única casa de Candomblé que encontramos na cidade de Monte Carmelo (dados acima). Desde o primeiro momento, fomos muito bem recebidas pela zeladora, que se mostrou satisfeita com as intenções do projeto, nos apresentou toda a casa e nos contou sua história dentro da religiosidade. Encontramos uma casa bem estruturada, com seus quartos de santo, barracão, ervas, assentamentos e axés plantados, e organizada a partir dos valores e princípios hierárquicos do Candomblé, desde a vestimenta até os preceitos.
A zeladora da casa também se disponibilizou auxiliar nosso projeto, vindo a ser uma das palestrantes do minicurso intitulado: "Um dialógo com as religiosidades de matriz africana", realizado como proposta de formação da equipe, aberto à comunidade. Ela também participou ativamente do lançamento da exposição fotográfica no Espaço Cultural da Secretaria Municipal de Cultura de Monte Carmelo, em dezembro de 2012, ocasião na qual preparou um vasto banquete com comidas típicas de terreiro. Além dos seus filhos e filhas de santo, também participaram do evento as lideranças de outras casas.

Figura 2 - Foto de elementos sagrados em casa de Candomblé Nação Jeje.

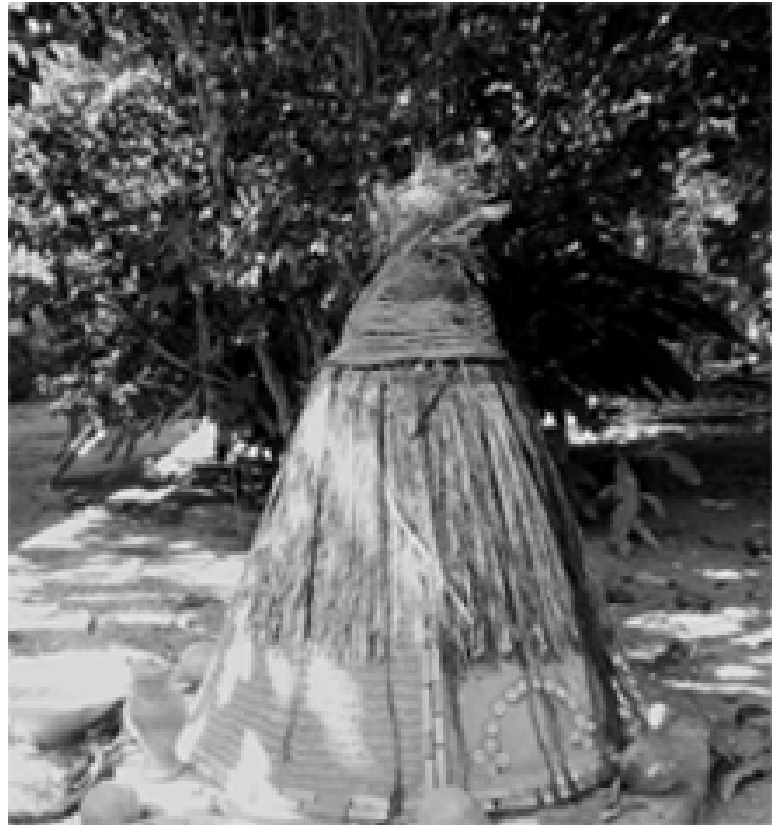

Fonte: Acervo do projeto. Dados: Hunkpámè Séja Hùn Atikògbé (Casa Onde os Espíritos das Árvores São Felizes). Fundação: 25/05/2006. Local: Uberlândia-MG. Zelador: Hugbono Adjahunsi.

O segundo registro fotográfico corresponde a uma das duas casas de Candomblé Jeje existentes na cidade de Uberlândia (dados acima), localizada no Setor de Chácaras, 
distante $15 \mathrm{~km}$ do centro comercial da cidade. $\mathrm{Na}$ visita, fomos muito bem recebidas pelo zelador Hugbono Adjahunsi e sua irmã, que vivem no local. A casa apresenta um espaço muito agradável, colorido, repleto de árvores, plantas, água, pássaros, assentamentos dos ancestrais e significados.

O zelador explicou que, apesar dos ancestrais em cada uma das nações (Angola, Ketu e Jeje) possuírem equivalências, uma das principais diferenças (notadas) no terreiro é a ausência do círculo durante as danças e os Voduns; estes, ao se manifestarem em terra por meio do corpo de algum adepto, geralmente conversam com as pessoas e ministram o que podemos chamar de "passe", fazendo o uso de perfumes, entre outros.

Figura 3 - Foto de saída de iaô em Candomblé Nação Ketu.

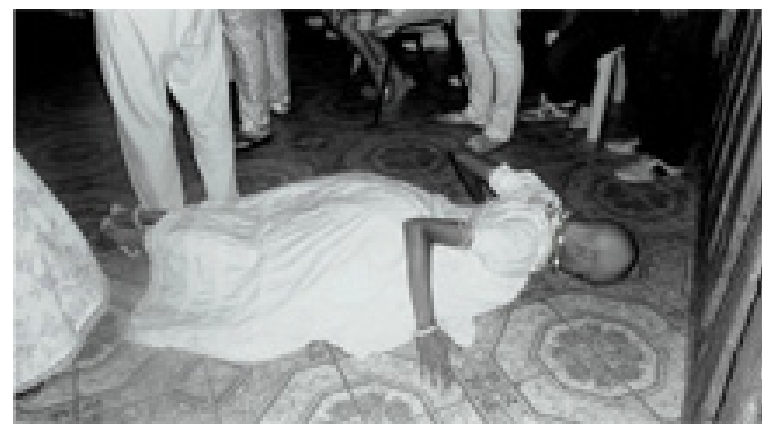

Fonte: Acervo do projeto. Dados: Ilê Alaketu ljobá Asè Sango (Casa de Ketu cujas forças são de Xangô). Fundação: por volta de 2006. Local: Uberlândia-MG. Zelador: Babalorixá Gilberto de Baru.

$\mathrm{Na}$ terceira imagem (dados acima), compartilhamos a comemoração da festa de saída de santo em uma casa de Candomblé de nação Ketu. O registro mostra o momento no qual a jovem iaô (nome dado aos fiéis recém iniciados) "bate cabeça" (nome dado à maneira de cumprimentar respeitosamente pessoas e locais sagrados) durante sua primeira saída na sala. Na festa, a iaô é apresentada à comunidade religiosa em seu novo status, agora de iniciada, ainda com a cabeça raspada, legitimando, assim, sua pertença ao grupo. Nessa casa, nosso projeto foi muito bem acolhido pelo zelador, Babalorixá Gilberto de Baru, que, na ocasião em que realizamos a observação de campo, durante a festa anual para seu Exu, nos concedeu um certificado da sua casa oferecido para pessoas que auxiliam na divulgação e na valorização das religiosidades de matriz africana. Percebemos nele uma pessoa sempre muito prestativa e rígida com seus filhos e filhas, demonstrando que em sua casa tudo passa severamente pelo seu crivo.

Com exceção das casas de Candomblé da Nação Jeje, todas as casas que participaram do projeto e que se auto-denominam pertencentes ao Candomblé também realizam, semanamente, sessões próprias da Umbanda, com algumas leves distinções. Tal fato é muito comum. Para Reginaldo Prandi (1991), pesquisador de Candomblés de São Paulo, essa é uma característica que se deve ao movimento de saída dos religiosos da Umbanda e entrada no Candomblé; todavia, ao se fazer essa passagem, esses religiosos levam consigo muito dos elementos significativos próprios da religiosidade anterior para a nova. Não se trata de ser algo impuro, segundo afirmam alguns autores, mas dos fiéis carregarem, transporem alguns elementos distintos ao longo de suas trajetórias religiosas, ampliandoos para um leque maior de possibilidades. 
Figura 4 - Foto de zelador diante do altar em casa de Umbanda.

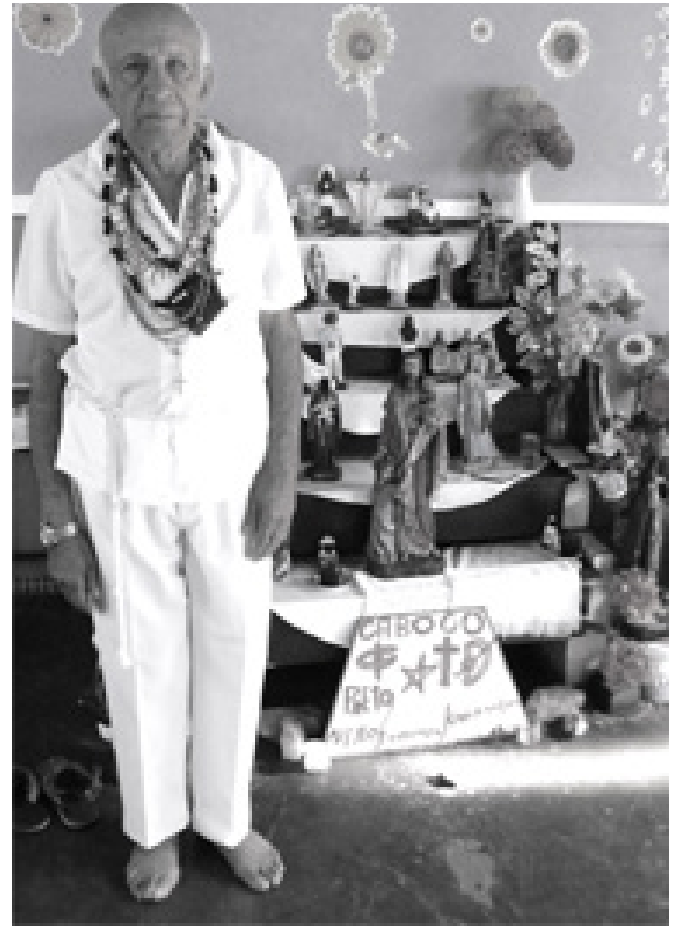

Fonte: Acervo do projeto. Dados: Casa Espírita de Ogum, Caboclo Pena Branca. Fundação: 1980. Local: ItuiutabaMG. Zelador: Pai Reinor de Ogum.

Na visita à casa representada no quarto registro fotográfico (dados acima), logo na chegada, percebemos que o zelador Pai Reinor está em outro momento, inserido em um tempo que reflete tranquilidade, harmonia e muita sabedoria. O Centro encontra-se ao lado de sua residência, com entrada independente. Fomos recebidos por ele e sua esposa que nos relataram sua trajetória na religiosidade até construir o Centro, além de nos apresentar todo o espaço e explicar o significado de cada local.

A fotografiadoaltar desseterreiroapresenta um panorama geral das entidades cultuadas na casa, em que é possível perceber a existência de um policulturalismo de elementos e símbolos (santos católicos, entidades africanas, escritos e desenhos), algo muito comum nas Umbandas.

O que nos chamou muita atenção foi à existência de um quarto com uma cama no local, que é utilizado para as sessões de cura realizadas pela entidade conhecida como "Caboclo Pena Branca", e uma pequena biblioteca do zelador, que recomenda algumas leituras aos que frequentam a casa, da mesma forma que também nos recomendou, para uma melhor compreensão das religiosidades de matriz africana.

Durante o lançamento da exposição fotográfica realizada em março de 2013, no Campus Pontal da Universidade Federal de Uberlândia, na cidade de Ituiutaba, Pai Reinor participou da mesa de abertura do evento, juntamente com o religioso Carlos e Tatá Marildo. Na ocasião, cada zelador compartilhou suas trajetórias e visões religiosas de mundo. $\mathrm{O}$ debate expôs que mesmo pertencentes a uma mesma matriz religiosa, há uma diversidade muito grande em cada casa pesquisada, pois além das distinções provocadas pela existência de diferentes nações, entre os Candomblés e as Umbandas, a própria personalidade de cada zelador irá moldar a essência da casa.

Figura 5 - Foto casa de Omoloko de Tata Inkice Utakao.

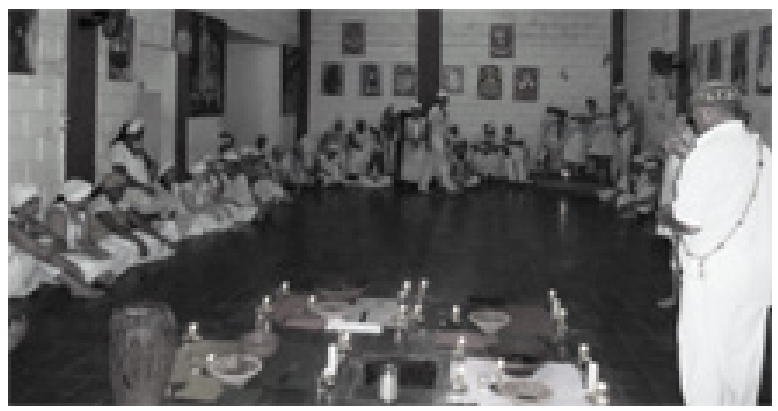

Fonte: Acervo do projeto. Dados: Centro de Filantropia Espiritual e Material Irmãos do Arco Íris. Fundação: 1991. Local: Uberlândia-MG. Zelador: Tata Inkice Utakao (Tata Davi).

No contato com a casa mostrada na Figura 
5 (dados acima), localizada em UberlândiaMG, percebemos que o zelador é muito respeitado tanto pela comunidade religiosa quanto pela sociedade em geral. Sua casa é uma das que possuem o maior número de fiéis.

Algo interessante verificado no local é a existência de vários pais e mães de santo. Alguns de seus filhos e filhas mais velhos tornaram-se tatetos (pais) e mametos (mães) de santo, convivendo todos no mesmo espaço, o que distingue este terreiro da maioria, em que existe apenas um zelador à frente da casa e que realiza todos os processos iniciativos, comanda as sessões, os rituais, e outros.

Segundo o Pai Davi Araujo, zelador da casa de Omolokô de Tata Inkice Utakao, o Omolokô é um culto de origem Nagô, cuja palavra significa $\mathrm{OMO}=$ nascido e LOKÔ = natureza (árvore). Em resumo, o Omolokô é o culto do homem com a natureza, com suas origens, seu poder criador. Representa uma explicação possível para a criação de tudo, com traços da cultura muçulmana: os quatro ÓS significam os quatro elementos responsáveis pela existência de vida no planeta: terra, ar, água e fogo; as letras: M L K, significam as iniciais das culturas MALÊS (Muçulmanos ou Muçurumins), povo de LUNDA e nação de KIOKO.

\section{Considerações Finais}

Por meio do projeto de extensão "Por que tanto preconceito: o cotidiano das religiosidades de matriz africana", nossa angústia na busca por estreitar os laços entre universidade e os sujeitos pertencentes às religiosidades de matriz africana, portadores de outros saberes, foram amenizadas.

Das idas a campo, contamos com a colaboraçãodezeladoresezeladorasqueabriram as portas de seus terreiros, compartilhando conosco um pouco de suas trajetórias na religiosidade e dos registros fotográficos do cotidiano das casas de Candomblé e Umbanda, em Monte Carmelo, Ituiutaba e Uberlândia, além das mesas redondas com debates, que antecederam duas das três exposições fotográficas abertas ao público em geral. Diante disso, acreditamos que, de fato, o projeto contribuiu para a divulgação e valorização da realidade concreta dos sujeitos envolvidos, direta e indiretamente, nessa matriz religiosa, configurando-se como uma importante bandeira de luta pela liberdade religiosa.

Consideramos que o projeto ampliou o conhecimento das diferentes formas de sentir o sagrado, a muito perseguidas e desconhecidas, que precisam ser respeitadas. Mas para isso, antes é necessário que a população conheça melhor as religiosidades de matriz africana, sendo essa a preocupação central do projeto.

Buscamos compartilhar e divulgar a diversidade dos rituais religiosos presentes no Triângulo Mineiro e Alto Paranaíba, contribuindo, desse modo, para ampliar o conhecimento sobre essa realidade, por parte da comunidade acadêmica e da sociedade em geral, principalmente por meio dos registros fotográficos - uma das linguagens mais acessíveis a todas as faixas etárias e níveis de escolaridade.

Portanto, a proposta visou contribuir para a diminuição do preconceito para com as religiosidades de matriz africana, algo que, na atualidade, apresenta-se como uma necessidade não só brasileira, mas mundial.

Finalizando nossas conclusões, mas não a temática em questão, consideramos que as práticas acadêmicas precisam estar voltadas para a busca de conhecimentos e a compreensão sobre o diferente e o novo, além de defenderem a liberdade de expressão dos oprimidos e subjugados por suas crenças, atitudes, performances e ações na realidade social; seja no campo da liberdade religiosa, sexual e ideológica, no campo das lutas sociais por terra e moradia ou em outros campos de atuação que, por vezes, são discriminados, antes mesmo de serem conhecidos a fundo. 


\section{Referências}

BÂ, A. H. Amkoullel, o menino fula. São Paulo: Palas Athena/Casa das Áfricas, 2003.

FREIRE. Paulo. Extensão ou comunicação. Rio de Janeiro. Paz e Terra. 1983.

INSTITUTO BRASILEIRO DE GEOGRAFIA E ESTATÍSTICA - IBGE. Censo Demográfico 2010.

Disponível em: <http://www.ibge.gov.br/home/estatistica/populacao/censo2010/tabelas_pdf/total_ populacao_minas_gerais.pdf >. Acesso: 5 abr. 2013.

NAVARRO, C. Ameaça à liberdade de culto. Jornal Brasil de Fato, São Paulo, 13 a 19 set. 2012, p. 4 e 5.

MOTT, L. De viado em Angola a diabo no Brasil. In: CONGRESSO LUSO-AFRO-BRASILEIRO DE CIÊNCIAS SOCIAIS, 9., 2011, Salvador. Anais... Salvador: Universidade Federal da Bahia, 2011.

PARÉS, L. N. A formação do candomblé: história e ritual da nação Jeje na Bahia. Campinas, SP: Editora da Unicamp, 2006.

PRANDI, R. Os candomblés de São Paulo: a velha magia na metrópole nova. São Paulo: HUCITEC/ EdUSP, 1991.

SILVA, V. G. da. Orixás da metrópole. Petrópolis: Vozes, 1995.

Submetido em 31 de outubro de 2012.

Aprovado em 14 de março de 2013. 